\title{
Protective Effects of Quercetin and Melatonin on Indomethacin Induced Gastric Ulcers in Rats
}

\author{
Marwa Sayed Abdel-Tawab*1, Ola Mostafa Tork ${ }^{2,3}$, \\ Gomaa Mostafa-Hedeab ${ }^{4,5}$, Manal Ewaiss Hassan ${ }^{1,6}$, Dalia Azmy Elberry ${ }^{3}$
}

\begin{abstract}
Background: Medications to prevent the development of NSAID-induced gastric ulcers have a large range of unpleasant side effects. Recent efforts have been focused on determining safer alternative nontoxic and natural forms of anti-ulcer treatments.

Methods: Twenty-four male rats were divided into 4 groups: 1: control group that received no treatment; 2: the indomethacin-treated group that received $20 \mathrm{mg} / \mathrm{kg}$ of indomethacin for 2 days to induce the development of gastric ulcers; 3: quercetin-treated group that in addition to the indomethacin treatment, received $50 \mathrm{mg} / \mathrm{kg}$ of quercetin 6 hours after and then daily for 14 days and; 4: the melatonin-treated group which received $20 \mathrm{mg} / \mathrm{kg}$ of melatonin 6 hours after each indomethacin treatment and then daily for 14 days. All drugs were administered orally. The following parameters were assessed in each group: mean ulcer index of gastric tissue, gastric acid volume and $\mathrm{pH}$, oxidative stress markers: malondialdehyde (MDA), superoxide dismutase (SOD), glutathione peroxidase (GSH), inflammatory markers: PGE-2, TNF- $\alpha$, and IL-10, nitric oxide (NO) levels and the relative gene expression of BAX, BCL-2 and COX-2 by real time PCR.
\end{abstract}

Results: Our findings revealed that the indomethacin-treated group had a significantly increased $(\mathrm{p}<0.05)$ ulcer index, gastric acid volume, and elevated levels of stress, inflammatory, and apoptotic markers compared to controls. In the groups that received quercetin or melatonin, these factors were all significantly decreased $(\mathrm{p}<0.05)$. Between quercetin and melatonin, there was no significant difference in their gastroprotective effect.

Conclusions: Both quercetin and melatonin had protective antioxidant, anti-inflammatory and antiapoptotic activity against indomethacin-induced gastric ulcers.

Keywords: Gastric ulcer, Indomethacin, Melatonin, Quercetin.

\section{Introduction}

Peptic ulcers are associated with severe complications including bleeding and perforation, which can lead to significant morbidity and mortality. Previous research suggests that a highly acidic gastric environment has a role in the formation of peptic ulcers.
However, the pathogenesis of peptic ulcers is multifactorial and occurs when the number of risk factors as smoking, drinking alcohol, stress, spicy food and regular use of NSAIDs outweigh the protective factors as mucus gel, mucus phospholipid, bicarbonate buffers,

1: Medical Biochemistry Department, Faculty of Medicine, Beni-Suef University, Egypt.

2: Basic Medical Science Department, Faculty of Medicine, Princess Nourah bint Abdulrahman University, Kingdom of Saudi Arabia.

3: Department of Medical Physiology, Faculty of Medicine, Cairo University, Egypt.

4: Pharmacology Department, Medical college, Jouf University, Kingdom of Saudi Arabia.

5: Pharmacology Department- Faculty of Medicine, Beni-Suef University, Egypt.

6: Medical Biochemistry Department, Faculty of Medicine, Al Jouf University, Kingdom of Saudi Arabia.

*Corresponding author: Marwa Sayed Abdel-Tawab; Tel: +2 01028328810; E-mail: drmarwasayed2016@gmail.com.

Received: 27 Apr, 2020; Accepted: 11 May, 2020 
prostaglandins, and gastric hormones (1).

Non-steroidal anti-inflammatory drugs (NSAIDs) are primarily indicated for pain and inflammation due to their anti-inflammatory and analgesic effects. They work by inhibiting the cyclooxygenase (COX) enzymes which are involved in the synthesis of many inflammatory mediators including prostaglandins, which also have a role in the production of pain (2). Despite these therapeutic effects, the inhibition of COX and subsequently prostaglandin activity, has been linked to the development of peptic ulcers. Some studies have indicated that there are additional prostaglandin-independent mechanisms involved in the pathogenesis of NSAID-induced peptic ulcers including generation of reactive oxygen species (ROS) (3), disorganizing the gastric mucosal membranes (4), NSAID-induced apoptosis (5), upregulation of proinflammatory cytokines as TNF- $\alpha$ (6) or disrupting gastric mucosal integrity by inhibition of constitutive nitric oxide synthase (cNOS) (6). Indomethacin (INDO) is one of the most harmful NSAIDs on the gastrointestinal tract (GI), causing significant injury to the mucosa. Therefore, this is commonly used to investigate the damaging effects of NSAIDs on the GI tract and the protective effects of potential treatments (7).

Anti-ulcer medications are indicated for the prevention and treatment of NSAID-induced gastric ulcers. However, they have a large and unpleasant adverse effect profile as diarrhea, GI disturbance, electrolytes imparlance, irregular heart rate, CNS symptoms and urinary symptoms (8). New efforts have been dedicated towards evaluating the use of alternative nontoxic and natural anti-ulcer treatments (9). Flavonoids are natural compounds with anti-inflammatory, antiallergic, anti-viral, anti-bacterial and antitumor activity (10). Quercetin (3, 5, 7, 3', 4'pentahydroxyflavone) is a flavonoid found in fruits and vegetables like onions, apples, berries, green and black tea (11). Experimental studies have shown a gastroprotective effect of quercetin in ethanol-induced gastric mucosal lesions (12). Melatonin (N-acetyl-5methoxytryptamine) is an endogenous molecule synthesized from tryptophan in the pineal gland and additional extra-pineal organs such as the skin, pancreas, kidneys, and liver. Increasing evidence has shown melatonin to have both anti-inflammatory and antioxidant effects in vivo and in vitro (13).

The aim of this study was to investigate the antioxidant, anti-inflammatory and antiapoptotic effects of quercetin and melatonin against indomethacin-induced gastric ulcers in an in vivo rat model.

\section{Materials and methods Animals}

The present study was conducted on 24 adult male Albino rats (120 -170 g). Animals were handled in the experimental animal unit, Faculty of Medicine, Cairo University from March 2019 to September 2019. The animals were adapted to a conditioned environment of $25^{\circ} \mathrm{C}$, humidity $50 \%-55 \%$, with a 12-h light/dark cycle for 10 days before beginning the experiment. They could freely access water and food and were housed in ideal conditions throughout the experiment.

\section{Ethics approval}

Our research follows internationally recognized guidelines on animal welfare. The experiments were performed in accordance with the guidelines for the care and use of experimental animals introduced by the USA National Institute of Health (NIH, 1985), and approved by the local ethical and scientific committee of Faculty of Medicine- Cairo University.

\section{Experimental design}

The rats were fasted for $24 \mathrm{~h}$ before the experiment and housed in wire mesh cages to prevent coprophagia (consumption of feces). Rats were allowed water up until one hour before the experiments (14). We performed our experiments at fixed times of the day between 9 a.m. and 1 p.m. to remove any potential confounding factors that may be related to the diurnal rhythms of gastric acid secretion (15).

The animals were randomly divided into four groups of six and treated as follows: Group 1 
(Control): Received $1 \mathrm{~mL}$ of $1 \%$ sodium carboxymethyl cellulose (CMC) orally for 14 days. Group 2 (INDO): To induce gastric ulcers, indomethacin (Sigma, Aldrich) was dissolved in $1 \% \mathrm{CMC}$ and administered orally at a dose of $20 \mathrm{mg} / \mathrm{kg}$ for 2 days, then received an oral dose $1 \%$ CMC for 14 days (16).

Group 3 (INDO+Q): Indomethacin was administered as in group 2. However, each day, 6 hours after indomethacin was administered the group would receive an oral dose (50 $\mathrm{mg} / \mathrm{kg}$ ) of quercetin (Sigma, St Louis, MO, USA) dissolved in $1 \% \mathrm{CMC}$ which continued for 14 days.

Group 4 (INDO+ M): The same indomethacin administration schedule was given as in group 2 and 3. Each day for 14 days, the group was given an oral dose $(20 \mathrm{mg} / \mathrm{kg})$ of Melatonin (Sigma, Saint Louis, Missouri, USA) dissolved in 1\% CMC 6 hours after their indomethacin treatment.

\section{Study procedures}

At the end of the experiment, animals in all studied groups were euthanized via cervical dislocation then they were dissected with taking out and opening of the stomach along the greater curvature using saline for washing. After that, the mucosa was exposed for gross evaluation with removing of some parts that are handled as mentioned thereafter for biochemical and molecular studies.

\section{Determining ulcer index}

According to Nishida et al., (17) and Peskar et al., (18) gastric lesions are expressed as an ulcer index (U.I.). This is determined according to the length and severity of the lesions and ranked using a 0-3 scoring system. The severity factor 0 indicates no lesions, 1 indicates lesions $<1 \mathrm{~mm}$ length, 2 indicates lesions 2-4 $\mathrm{mm}$ length, and 3 indicates lesions $>4 \mathrm{~mm}$ length. The ulcer index of each rat in the drug-treated groups was calculated as lesion number of the rat multiplied by their respective severity factor. The mean lesion score for each rat was calculated in all treated groups.

\section{Microscopic examination}

According to Kiernan (19), histopathological examination with Hematoxylin \& Eosin (H\&E) staining was done at the histology department of the faculty of Medicine at Cairo University.

\section{Gastric juice volume and $\mathrm{pH}$}

After exposing the stomach and duodenum, a small incision in the duodenum was made to insert a poly-ethane tube into the stomach and was fixed by pylorus ligation. Clamping of esophagus was done prevent gastric secretions refluxing upward resulting in the loss of volume. The gastric juice was collected in tubes and centrifuged at $5000 \times \mathrm{g}$ for $5 \mathrm{~min}$, the supernatant volume was obtained and expressed as $\mathrm{mL} / 100 \mathrm{~g}$ b.w. The extracted gastric acid was assessed via titration with 0.01 Normal $\mathrm{NaOH}$ and using phenolphthalein as an indicator. A graduated cylinder was used to assess the volume of gastric juice which was expressed in $\mathrm{ml}$. The $\mathrm{pH}$ meter was used to assess gastric juice ph.

The gastric mucosae of all rats in each group were rubbed off and separated into 2 parts. One part to examine COX-2, BCL-2 and BAX relative gene expression. The other part for biochemical analysis. This second section was homogenized in $0.02 \mathrm{M}$ of ice-cold phosphate buffer saline at $\mathrm{pH} 7.2$ to get $10 \%$ aqueous homogenates which were centrifuged for 30 minutes at $5000 \times \mathrm{g}$. The supernatant was assessed for inflammatory and oxidative stress markers.

\section{Relative gene expression of $B A X, B C L-2$, and COX-2}

Gastric tissue samples were lysed followed by total RNA isolation with RNeasy purification reagent (Qiagen, Valencia, CA,). The spectrophotometer was used to measure total RNA purity with a wavelength absorption ratio $(260 / 280 \mathrm{~nm})$, ranging from 1.8 to 2.0 for all samples. cDNA was transcribed from total RNA using the reverse transcriptase Superscript II, Gibco Life Technologies, Grand Island, NY, USA kit.

The Applied Biosystems software version 
3.1 (StepOneTM, USA) was used for quantitative qRT-PCR analysis. We mixed SYBR Green Master Mix (Applied Biosystems), gene-specific primer pairs (shown in Table 1), and cDNA and nuclease-free water.
Amplification conditions were set according to the manufacturer specifications: $2 \mathrm{~min}$ at $50{ }^{\circ} \mathrm{C}$, $10 \mathrm{~min}$ at $95^{\circ} \mathrm{C}$, then 40 cycles of denaturation at $95{ }^{\circ} \mathrm{C}$ for $15 \mathrm{~s}$ then annealing/ final extension at $60{ }^{\circ} \mathrm{C}$ for $10 \mathrm{~min}$.

Table 1. Primer Sequences of studied genes.

\begin{tabular}{lll}
\hline \multicolumn{1}{c}{ Gene } & \multicolumn{1}{c}{ Sequence } & \multicolumn{1}{c}{$\begin{array}{c}\text { Gene bank } \\
\text { accession number }\end{array}$} \\
\hline $\boldsymbol{B} \boldsymbol{A} \boldsymbol{X}$ & $\begin{array}{l}\text { Forward primer: 5'-GGGACGAACTGGACAGTAACAT-3' Reverse } \\
\text { primer: 3'-GGGACGAACTGGACAGTAACAT-3' }\end{array}$ & NM_017059 \\
\hline $\boldsymbol{B} \boldsymbol{C} \boldsymbol{L}-\mathbf{2}$ & $\begin{array}{l}\text { Forward primer: 5'-CATGTGTGTGGAGAGCGTCAA3' } \\
\text { Reverse primer: 5'-GCCGGTTCAGGTACTCAGTCA-3' }\end{array}$ & NM_016993 \\
\hline $\boldsymbol{C} \boldsymbol{O \boldsymbol { X } \mathbf { - 2 }}$ & $\begin{array}{l}\text { Forward primer: 5'-GATTGACAGCCCACCAACTT -3' } \\
\text { Reverse primer: 5'-CGGGATGAACTCTCTCCTCA -3' }\end{array}$ & NM_017232 149 \\
\hline \multirow{2}{*}{ Beta actin } & $\begin{array}{l}\text { Forward primer: 5' - 5'-ATGAGCCCCAGCCTTCTCCAT -3' } \\
\text { Reverse primer: 5' - CCAGCCGAGCCACATCGCTC -3' }\end{array}$ & NM_007393 \\
\hline
\end{tabular}

\section{Calculation of relative quantification (relative expression)}

The comparative cycle threshold method (20) was used to calculate relative gene expression. All results were standardized to $\beta$-actin mRNA as an internal calibrator in all samples. Relative quantitation of target gene expressions (RQ) was calculated using the following equation:

$\Delta \mathrm{Ct}=\mathrm{Ct}$ assessed gene $-\mathrm{Ct}$ reference gene $\Delta \Delta \mathrm{Ct}=\Delta \mathrm{Ct}$ sample $-\Delta \mathrm{Ct}$ control gene $\mathrm{RQ}=2^{-(\Delta \Delta \mathrm{Ct})}$

\section{Inflammatory markers assessment (PGE2, IL- 10, TNF- $\alpha$ )}

The levels of PGE2 (dosage kit from R\&D Systems (USA), TNF- $\alpha$ (Diagnostic Products Corp., Los Angeles, CA, USA) and IL-10 (Cat No. ELR-IL10-001), RayBio, MO, USA) in the homogenates of gastric tissues were evaluated by ELISA according to the manufacturer's instructions. The color intensity was directly proportional to the concentration of PGE2, TNF- $\alpha$ and IL-10 present in the samples. The gastric concentrations of PGE2, TNF- $\alpha$ and IL10 levels were expressed as $\mathrm{pg} / \mathrm{mg}$ tissue.

\section{Oxidative stress markers (MDA, SOD, GSH, NO)}

The spectrophotometer was used to determine the gastric levels of malondialdehyde (MDA), superoxide dismutase (SOD) and reduced glutathione (GSH) using bio diagnostic kits (Dokki, Giza, Egypt).

\section{MDA assay}

Malondialdehyde (MDA) is one of the many end products formed through lipid peroxidation. Using the Thiobarbituric acid reactive substance (TBARS) method (21), the level of MDA present in the gastric homogenates was measured according to the manufacturer's instructions. $50 \mu \mathrm{L}$ of tissue supernatant was put in test tubes containing 2 $\mu \mathrm{L}$ of butylated hydroxytoluene (BHT). Then, $50 \mu \mathrm{L}$ of $1 \mathrm{M}$ phosphoric acid and $50 \mu \mathrm{L}$ of Thiobarbituric acid solution was added. After thorough mixing, the tubes were incubated at $60{ }^{\circ} \mathrm{C}$ for $60 \mathrm{~min}$ then centrifuged at $1600 \times \mathrm{g}$ for $10 \mathrm{~min}$ at $4{ }^{\circ} \mathrm{C}$. The absorbance of the supernatant was measured at $532 \mathrm{~nm}$. Gastric MDA levels were expressed as $\mathrm{nmol} / \mathrm{mg}$ tissue (Bio diagnostic kits (Dokki, Giza, Egypt).

\section{SOD assay}

According to Bradford method (22), gastric levels of SOD were assessed. Hypoxanthine and xanthine oxidase were used to generate superoxide radicals to react with a tetrazolium salt to produce a formazan dye at $440 \mathrm{~nm}$. Superoxide dismutase converts superoxide to 
hydrogen peroxide, inhibiting this reaction thus leading to a decrease in the amount of formazan dye. The measured SOD gastric levels were expressed as $\mathrm{u} / \mathrm{mg}$ tissue.

\section{GSH assay}

To measure the levels of gastric GSH, the Griffith method was used (23) using 2vinylpyridine (2VP) as the GSH masking agent. The gastric tissues were frozen on solid $\mathrm{CO} 2$ and stored at $-80{ }^{\circ} \mathrm{C}$ until performing the assay. The frozen tissues were then homogenized in ice cold 3\% sulfosalicylic acid (SSA) containing $0.1 \mathrm{mM}$ EDTA and $0.2 \mathrm{mM}$ sucrose at $\mathrm{pH} 7.5$. The homogenate was then precipitated with ice-cold $25 \%$ Trichloroacetic acid $(0.1 \mathrm{~mL})$ and centrifuged for 40 minutes $(4$ ${ }^{\circ} \mathrm{C}, 4000 \times \mathrm{g}$ ). The GSH levels were assessed in the supernatant at $412 \mathrm{~nm}$. Gastric GSH levels were expressed as nmol/mg tissue.

\section{Nitric oxide (NO) assay}

The spectrophotometer was used to determine the gastric levels of $\mathrm{NO}$ using colorimetric assay kit (Elx800, Bio-TEK Ins., USA). Nitric oxide end products in the gastric mucosa are nitrite and nitrate, therefore the concentration of NO can be indirectly measured by detecting the concentration of nitrate or nitrite (24). $50 \mu \mathrm{L}$ of Griess reagent was added to 50 $\mu \mathrm{L}$ of gastric mucosa homogenate and incubated at room temperature for $10 \mathrm{~min}$. The NO levels were assessed at $540 \mathrm{~nm}$ and calculated from a NaNO2 standard curve. The gastric NO levels were expressed as $\mathrm{nmol} / \mathrm{mg}$ tissue.

\section{Statistical analysis}

The SPSS statistical software package (version 24; IBM, New York, USA) was used for statistical analysis, including determining the mean and standard deviation. Analysis of variance (ANOVA) with multiple comparisons post hoc test was used for comparing between groups. Spearman correlation coefficient was used to show the relationship between quantitative variables. Results were considered statistically significant if P-values were less than 0.05 .

\section{Results}

\section{Macroscopic examination}

As shown in Table 2, the ulcer index in the $\mathrm{INDO}+\mathrm{Q}$ group and INDO+M group was significantly decreased $(\mathrm{p}<0.05)$ compared to the INDO group.

Table 2. The effects of treatment on ulcer index, gastric acid volume and gastric $\mathrm{pH}$.

\begin{tabular}{|c|c|c|c|c|}
\hline & $\begin{array}{c}\text { Control Group } \\
(\mathrm{N}=6) \\
\mathrm{M} \pm \mathrm{SD}\end{array}$ & $\begin{array}{l}\text { INDO Group } \\
(\mathrm{N}=6) \\
\mathrm{M} \pm \mathrm{SD}\end{array}$ & $\begin{array}{c}\text { INDO+Q Group } \\
(\mathrm{N}=6) \\
\mathrm{M} \pm \mathrm{SD}\end{array}$ & $\begin{array}{c}\text { INDO+M Group } \\
(\mathbf{N}=\mathbf{6}) \\
\mathbf{M} \pm \mathbf{S D}\end{array}$ \\
\hline Ulcer Index (mm) & 0.00 & $22.57 \pm 6.86 *$ & $7.60 \pm 2.33 * \#$ & $8.50 \pm 2.80 * \#$ \\
\hline Volume (ml) & $2.33 \pm 0.41$ & $4.69 \pm 0.37 *$ & $3.10 \pm 0.57 \#$ & $2.89 \pm 0.56 \#$ \\
\hline pH & $3.75 \pm 0.34$ & $2.78 \pm 0.25 *$ & $3.34 \pm 0.35 \#$ & $3.21 \pm 0.40$ \\
\hline
\end{tabular}

$\mathrm{N}$ : number of rats, $\mathrm{M} \pm \mathrm{SD}$ : Mean \pm Standard deviation,

*: Statistically significant as compared with control at $\mathrm{p} \leq 0.05$.

\#: Statistically significant as compared with INDO group at $p \leq 0.05$.

\section{Gastric acid volume and $\mathrm{pH}$}

There was a significant increase $(\mathrm{p}<0.05)$ in the gastric acid volume and a significant decrease $(\mathrm{p}<0.05)$ in $\mathrm{pH}$ levels in the INDO group compared to the control group, as shown in Table 2. These effects were significantly ( $\mathrm{p}<$ $0.05)$ reversed in the INDO+Q group and $\mathrm{NDO}+\mathrm{M}$ group and were comparable to the levels in control group.

\section{Oxidative stress markers}

Table 3 and Figure 1 show a significant increase $(p<0.05)$ in the mean tissue levels of MDA and a significant decrease $(p<0.05)$ in the mean tissue levels of GSH, SOD, and NO in INDO group compared to the control group. These effects were significantly $(\mathrm{p}<0.05)$ reversed in INDO+Q group and INDO+M group however, the levels of GSH and SOD 
remained significantly decreased $(\mathrm{p}<0.05)$ in these two groups compared to controls.

Table 3. The effects of treatment on the levels of oxidative stress markers within the gastric tissue.

\begin{tabular}{|c|c|c|c|c|}
\hline & $\begin{array}{c}\text { Control Group } \\
(\mathrm{N}=6) \\
\mathrm{M} \pm \mathrm{SD} \\
\end{array}$ & $\begin{array}{c}\text { INDO Group } \\
(\mathrm{N}=6) \\
\mathrm{M} \pm \mathrm{SD} \\
\end{array}$ & $\begin{array}{c}\text { INDO+Q Group } \\
(\mathrm{N}=6) \\
\mathrm{M} \pm \mathrm{SD} \\
\end{array}$ & $\begin{array}{c}\text { INDO+M Group } \\
(\mathrm{N}=6) \\
\mathrm{M} \pm \mathrm{SD}\end{array}$ \\
\hline MDA (nmol/mg tissue) & $13.62 \pm 3.38$ & $59.73 \pm 11.20^{*}$ & $22.54 \pm 4.41 * \#$ & $24.31 \pm 7.24 * \#$ \\
\hline NO (nmol/mg Tissue) & $25.15 \pm 8.64$ & $8.02 \pm 2.75 *$ & $19.87 \pm 3.16 \#$ & $20.30 \pm 5.68 \#$ \\
\hline GSH (mmol/mg tissue) & $62.02 \pm 9.47$ & $22.18 \pm 5.42 *$ & $47.4667 \pm 6.28 * \#$ & $49.70 \pm 4.59 * \#$ \\
\hline SOD (u/mg tissue) & $5.46 \pm 1.064$ & $1.003 \pm 0.19 *$ & $3.55 \pm 0.83 * \#$ & $3.77 \pm 0.77 * \#$ \\
\hline
\end{tabular}

$\mathrm{N}$ : number of rats, $\mathrm{M} \pm \mathrm{SD}$ : Mean \pm Standard deviation

*: Statistically significant as compared with control at $\mathrm{p} \leq 0.05$.

\#: Statistically significant as compared with INDO group at $\mathrm{p} \leq 0.05$.

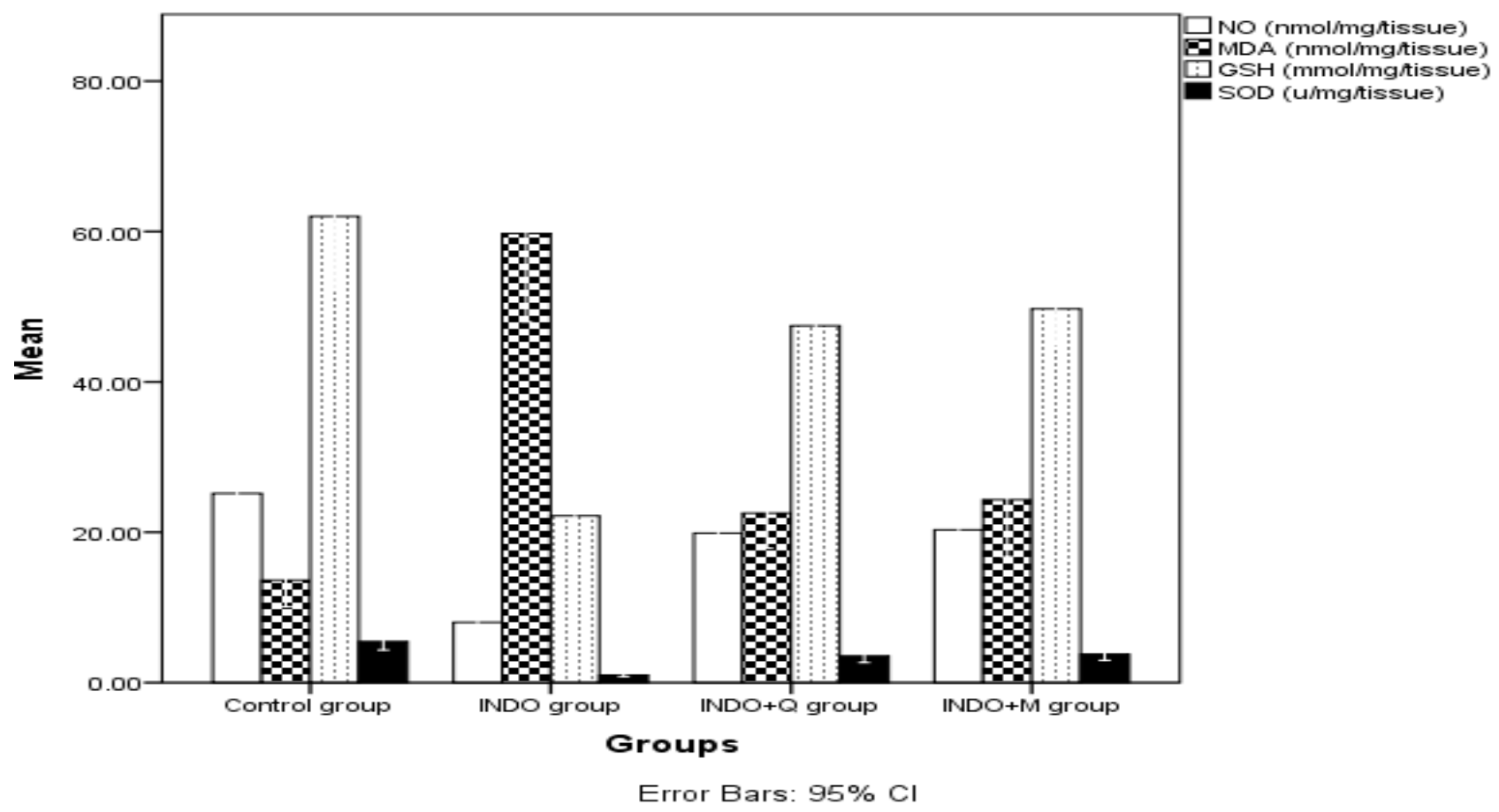

Fig. 1. The mean tissue levels of the oxidative stress markers in the control, INDO, INDO+Q and INDO+M groups.

\section{Pro-inflammatory and anti-inflammatory markers}

Our findings show a significant increase $(\mathrm{p}<$ 0.05 ) in the mean tissue levels of both PGE-2 and TNF- $\alpha$ and the upregulation of COX-2 gene in the indomethacin-treated group. Additionally, we observed a significant decrease $(p<0.05)$ in the mean tissue levels of IL-10 compared to the control group, as indicated in Table 4 and Figure 2. These effects were significantly $(\mathrm{p}<0.05)$ reversed in quercetin-treated rats (INDO+Q group) and melatonin-treated rats (INDO+M group) compared to indomethacin-treated rats (INDO group), however their levels were not normalized to the levels of the control group.

\section{Apoptosis markers}

Table 5 shows a significant decrease $(\mathrm{p}<0.05)$ in the relative gene expression of BCL-2 and a significant increase $(p<0.05)$ in relative gene expression of BAX in the indomethacin-treated rats (INDO group) compared to the control group. These effects were significantly $(\mathrm{p}<$ 0.05) reversed in quercetin-treated rats (INDO+Q group) and melatonin-treated rats (INDO+M group), however their levels were not normalized to the levels of the controls. 
The significant correlations found between the examined study parameters are shown in Figure 3. Our findings indicate a significant positive correlation between $\mathrm{COX} 2$ and TNF- $\alpha$ $(\mathrm{r}=0.812, \mathrm{p}=0.050)$ in both the INDO and INDO+Q groups. In the INDO+Q group, there was a significant negative correlation between the volume of gastric juice and BCL2 ( $\mathrm{r}=$ $0.823, \mathrm{p}=0.044)$ and between IL-10 and TNF- $\alpha$ $(\mathrm{r}=-0.924, \mathrm{p}=0.009)$. In the INDO+M group there was a significant negative correlation between MDA and BCL2 ( $r=-0.817, \mathrm{p}=0.047)$.

Table 4. The effects of treatment on the levels of inflammatory markers within the gastric tissue.

\begin{tabular}{|c|c|c|c|c|}
\hline & $\begin{array}{l}\text { Control Group } \\
\qquad \begin{array}{c}(\mathrm{N}=6) \\
\mathrm{M} \pm \mathrm{SD}\end{array}\end{array}$ & $\begin{array}{l}\text { INDO Group } \\
\begin{array}{c}(\mathrm{N}=6) \\
\mathrm{M} \pm \mathrm{SD}\end{array}\end{array}$ & $\begin{array}{c}\text { INDO+Q Group } \\
\left(\begin{array}{c}\mathrm{N}=6) \\
\mathrm{M} \pm \mathrm{SD}\end{array}\right.\end{array}$ & $\begin{array}{c}\text { INDO+M Group } \\
\begin{array}{c}(\mathrm{N}=6) \\
\mathrm{M} \pm \mathrm{SD}\end{array}\end{array}$ \\
\hline PGE2 (pg/mg tissue) & $117.97 \pm 6.52$ & $284.26 \pm 49.28 *$ & $176.23 \pm 26.63 * \#$ & $172.55 \pm 31.34 * \#$ \\
\hline TNF Alpha (pg/mg tissue) & $31.08 \pm 4.70$ & $86.98 \pm 13.86 *$ & $49.73 \pm 6.07 * \#$ & $47.22 \pm 12.38 \#$ \\
\hline IL-10 (pg/mg tissue) & $138.05 \pm 19.00$ & $58.80 \pm 15.28 *$ & $115.58 \pm 8.73 * \#$ & $110.48 \pm 12.82 * \#$ \\
\hline $\begin{array}{l}\text { COX2 (Relative } \\
\text { Expression) }\end{array}$ & $1.02 \pm 0.03$ & $6.78 \pm 1.25 *$ & $2.55 \pm 0.78 * \#$ & $2.73 \pm 0.56^{* \#}$ \\
\hline
\end{tabular}

$\mathrm{N}$ : number of rats, $\mathrm{M} \pm \mathrm{SD}$ : Mean \pm Standard deviation

*: Statistically significant as compared with control at $\mathrm{p} \leq 0.05$.

\#: Statistically significant as compared with INDO group at $\mathrm{p} \leq 0.05$.
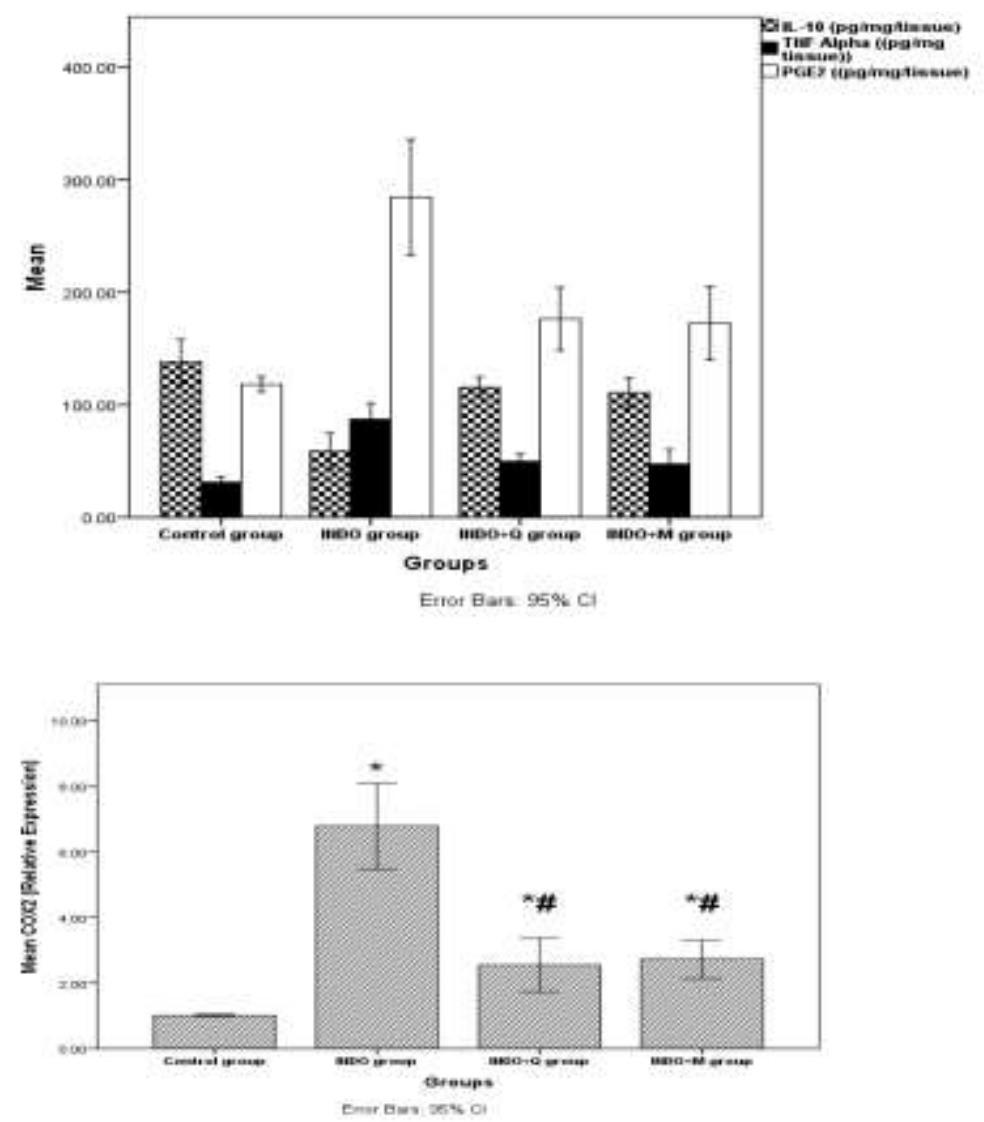

Fig. 2. The mean tissue levels of the inflammatory markers in the control, INDO, INDO+Q, and INDO+M groups.

*: Statistically significant as compared with control at $\mathrm{p} \leq 0.05$.

\#: Statistically significant as compared with INDO group at $\mathrm{p} \leq 0.05$. 
Table 5. The effects of treatment on the levels of apoptosis markers within gastric tissue.

\begin{tabular}{lcccc}
\hline & $\begin{array}{c}\text { Control group } \\
(\mathbf{N}=\mathbf{6}) \\
\mathbf{M} \pm \mathbf{S D}\end{array}$ & $\begin{array}{c}\text { INDO group } \\
(\mathbf{N}=\mathbf{6}) \\
\mathbf{M} \pm \mathbf{S D}\end{array}$ & $\begin{array}{c}\text { INDO+Q Group } \\
(\mathbf{N}=\mathbf{6}) \\
\mathbf{M} \pm \mathbf{S D}\end{array}$ & $\begin{array}{c}\text { INDO+M Group } \\
(\mathbf{N}=\mathbf{6}) \\
\mathbf{M} \pm \mathbf{S D}\end{array}$ \\
\hline $\begin{array}{l}\text { BAX (Relative Expression) } \\
\text { BCL2 (Relative }\end{array}$ & $1.00 \pm 0.02$ & $6.65 \pm 1.79 *$ & $2.50 \pm 0.44 * \#$ & $2.37 \pm 0.80 * \#$ \\
Expression) & $1.02 \pm .032$ & $0.23 \pm 0.13 *$ & $0.77 \pm 0.12 * \#$ & $0.76 \pm 0.104 * \#$ \\
\hline
\end{tabular}

$\mathrm{N}$ : number of rats, $\mathrm{M} \pm \mathrm{SD}$ : Mean \pm Standard deviation.

*: Statistically significant as compared with control at $\mathrm{p} \leq 0.05$.

\#: Statistically significant as compared with INDO group at $\mathrm{p} \leq 0.05$.
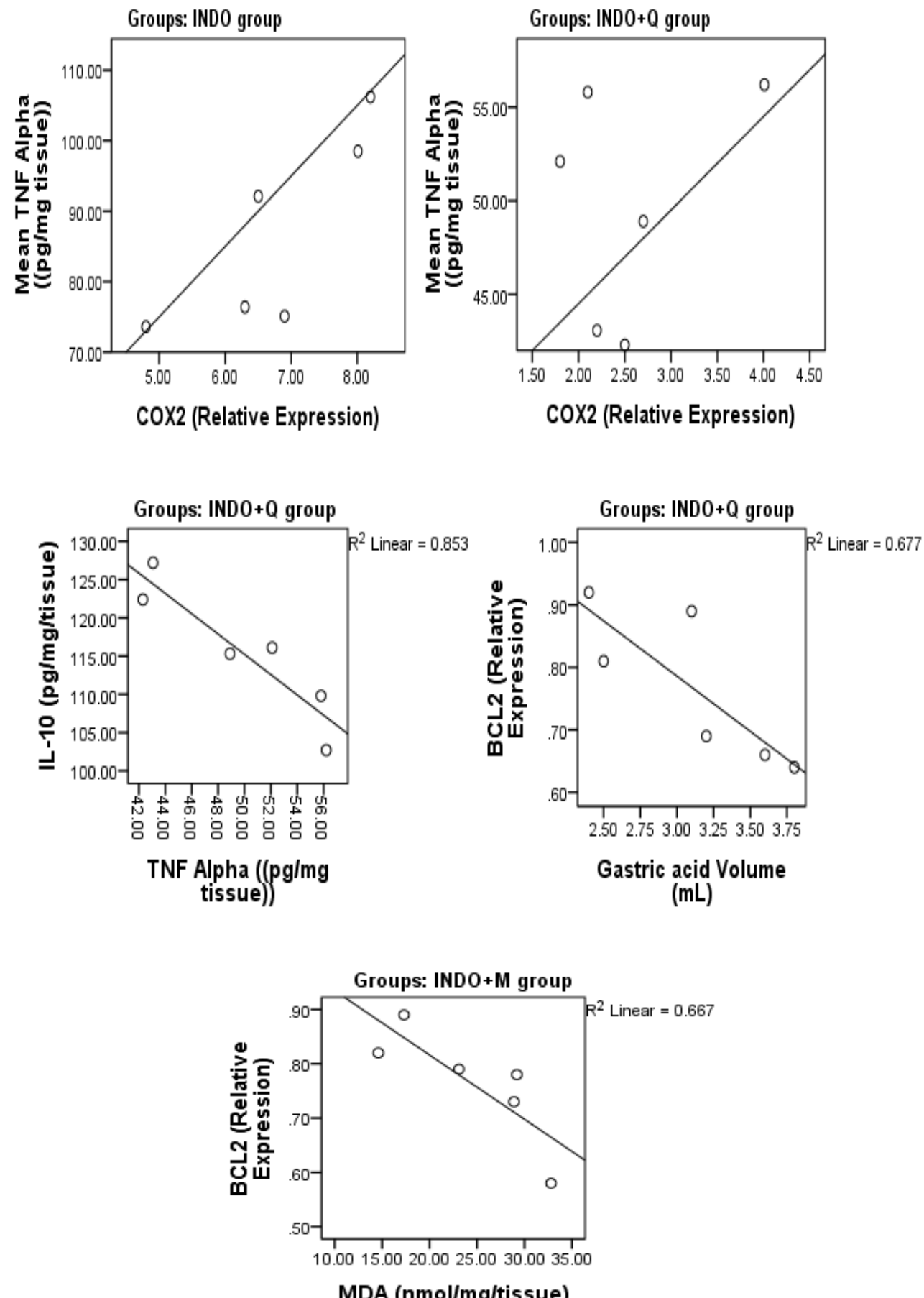

Fig. 3. Significant correlations found between the studied parameters in the control, INDO, INDO+Q, and INDO+M groups. 


\section{Microscopic examination results}

Figure 4 shows the focal necrosis and atrophy present in the mucosal layer of the stomach, with inflammatory cell infiltration in the base of mucosal layer and lamina propria in INDO-treated group. In the quercetin-treated and melatonin-treated groups there was little inflammatory cell infiltration and edema in the lamina propria and within the normal mucosal layer. Additionally, the basement membrane remained intact.

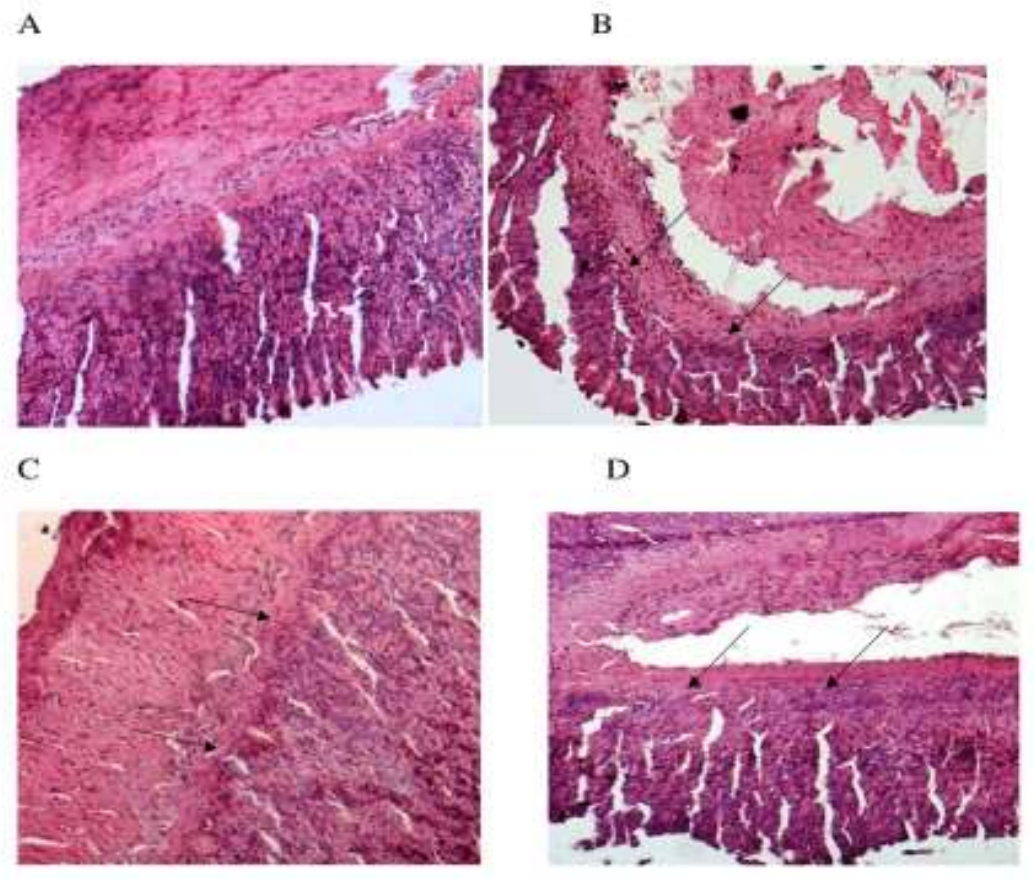

Fig. 4. Histological sections of the stomach of rats in the control, INDO, INDO+Q, and INDO+M groups (H\&E staining, $\times 400$ ). Histopathological results of rat stomach tissue of the control group (A) showed intact histological structures of the mucosal layer of gastric tissue. (B) In the INDO group that received indomethacin treatment to induce gastric ulcers, there was focal necrosis and atrophy in the mucosal layer and inflammatory cell infiltration in the base of mucosal layer and lamina propria (B). In the quercetin-treated (INDO+Q) group (C) and melatonin-treated (INDO+M) group (D) there was little inflammatory cell infiltration in the lamina propria and edema with normal mucosal layer and intact basement membrane.

\section{Discussion}

The development of NSAID-induced gastric ulcers is primarily the result of their interference with prostaglandin synthesis via the inhibition of COX enzymes, COX-1 and COX-2 (25). However, recent studies have suggested that prostaglandin-independent mechanisms play a role in contributing to the development of gastric ulcers such as the generation of reactive oxygen species (ROS) (3), the alteration of lipid organization the gastric mucosal membranes (4), NSAID-induced apoptosis (5), upregulation of pro-inflammatory cytokines including TNF- $\alpha$, or disrupting gastric mucosal integrity by inhibiting constitutive nitric oxide synthase (cNOS) (6). Both COX-1 and COX-2 hold a critical role in maintaining the integrity of the gastric tissue; COX-1 is involved in protecting the gastric mucosa while COX-2 is involved in healing gastric ulcers (26).

In the present study, we evaluated the role of oxidative stress, inflammation, and apoptosis in indomethacin-induced gastric ulcers and the potential protective effects of quercetin and melatonin. Our findings showed signs of inflammation in the indomethacin-treated group, indicated by the significant upregulation of the 
COX-2 gene, the inflammatory markers, PGE2 and TNF- $\alpha$, and a significant decrease in the mean tissue levels of the anti-inflammatory marker, IL10. Further evidence for inflammation is shown in the histological findings of focal necrosis and atrophy in the gastric mucosal layer and inflammatory cell infiltration at the base of gastric mucosal layer and lamina propria. Additionally, we found a significant positive correlation between COX-2 and TNF- $\alpha$ in both the indomethacin-treated and quercetin-treated group, and a significant negative correlation between TNF- $\alpha$ and IL-10 in the quercetin-treated group. These findings suggest that quercetin modulates the inflammatory changes caused by indomethacin treatment by decreasing the levels of proinflammatory markers and increasing the levels of anti-inflammatory markers.

Furthermore, we observed a significant increase in gastric volume and ulcer index and a significant decrease in gastric $\mathrm{pH}$ in the indomethacin-treated group compared to controls. In both the melatonin and quercetin treated groups all biochemical and histological indications of inflammation were not present, suggesting their role as anti-inflammatory and anti-ulcer treatments. Our findings corroborate previous work by Alkushi and Elsawy (27) who also reported increased gastric acid volume, ulcer index, and gastric $\mathrm{pH}$ in indomethacin-treated rats. Additionally, they found that quercetin treatment showed a marked decrease in the indomethacin-induced gastric damage suggesting antioxidant and gastroprotective effects (28). Similar results were reported by Ibrahim et al., (28).Our findings on the anti-inflammatory activity of melatonin corroborates previous work by Cuesta et al., (29) in which they reported that the administration of exogenous melatonin in old mice significantly lowered the expression of TNF- $\alpha$, IL-1 $\beta$, and IL-6 and increased the expression of IL-10 (29). However, Konturek et al., (30) concluded that the gastroprotective effect of melatonin occurs due to the activation of the COX-prostaglandin E (2) (PGE-2) system. Carrasco et al., (31) found similar results regarding the anti-inflammatory effects of quercetin in protecting the GI tract from gastric ulcer development through the downregulation of pro-inflammatory cytokines, including TNF- $\alpha$.

In the present study, the upregulation of COX2 and the secondary increase in PGE-2 may be explained by the gastric injury and inflammation caused by indomethacin. Within the healthy gastric mucosa, $\mathrm{COX}-1$ is constitutively expressed while COX-2 has low or minimal expression. $\mathrm{COX}-2$ is upregulated in response to NSAID-induced COX-1 inhibition, gastric injury and ulcers (32). This study showed a significant increase in the mean gastric levels of the lipid peroxidation by-product, MDA, and a significant decrease in the mean gastric levels of the antioxidant enzymes, GSH and SOD, in the indomethacin-treated group compared to control group. These findings suggest a role for ROS in damaging the mucosal surface of indomethacintreated rats. These results were significantly reversed in the quercetin-treated and melatonintreated groups, indicating their antioxidant effect by counteracting the oxidative stress generated by indomethacin. These results have been reported in previous work $(27,33)$.

In addition, there was a significant decrease in the mean tissue levels of NO in the indomethacintreated group compared to the control group. This effect was significantly reversed in rats treated with quercetin or melatonin. These results could be explained by previous studies which suggest that NO contributes to the development of NSAID-induced gastric ulcers via the induction of inducible nitric oxide synthase (iNOS) which produces high levels of $\mathrm{NO}$ or a decrease in constitutive nitric oxide synthase (cNOS) leading to low NO levels $(34,35)$.

Our findings showed a significant downregulation of BCL-2 and a significant upregulation of BAX in the indomethacin-treated group compared to controls. These effects were significantly reverse in rats treated with quercetin or melatonin. This suggests that both melatonin and quercetin have an antiapoptotic effect against indomethacin-induced apoptosis in gastric tissue. These results are corroborated by previous work by Maity et al., (36) in which their findings also suggest that melatonin can prevent indomethacininduced apoptosis. 
Furthermore, we observed a significant negative correlation between MDA and BCL2 in the melatonin-treated group. The use of NSAIDs can result in disruption of the mitochondrial trans-membrane potential and increase the permeability of the mitochondrial permeability transition pore (mPTP), leading to the mobilization of cytochrome c. This contributes to the production of ROS and induction of apoptosis. Therefore, our findings indicate that melatonin can inhibit NSAIDinduced apoptosis via its antioxidant activity and scavenging of ROS (37).

To our knowledge, no previous studies have reported the anti-apoptotic effect of quercetin against NSAID-induced gastric ulcers. Ishikawa \& Kitamura (38) showed an anti-apoptotic effect of quercetin in cultured mesangial cells that was mediated through blocking the JNK and ERK-mediated apoptotic pathways. In contrast, some studies suggest that the anticancer effect of quercetin is mediated via the

\section{References}

1. Tsai TC, Brooks DC. Evaluation of Peptic Ulcer Disease. In: Grams J., Perry K., Tavakkoli A. (eds) The SAGES Manual of Foregut Surgery. Springer, Cham. 2019; pp 635-642.

2. Jahnavi K, Pavani Reddy P, Vasudha B, Narender B. Non-steroidal antiinflammatory drugs: an overview. Journal of Drug Delivery and Therapeutics. 2019;9(1-s):442-448.

3. Naito Y, Yoshikawa T. Oxidative stress involvement and gene expression in indomethacin-induced gastropathy. Redox Rep. 2006;11(6):243-53.

4. Lichtenberger LM, Zhou Y, Dial EJ, Raphael RM. NSAID injury to the gastrointestinal tract: evidence that NSAIDs interact with phospholipids to weaken the hydrophobic surface barrier and induce the formation of unstable pores in membranes. J Pharm Pharmacol. 2006;58(11): 1421-8.

5. Jana NR. NSAIDs and apoptosis. Cell Mol Life Sci. 2008;65(9):1295-301.

6. Souza MH, Lemos HP, Oliveira RB, Cunha FQ. Gastric damage and granulocyte infiltration induction of apoptosis in cancer cells $(39,40)$.

In this study, there was a significant negative correlation between the volume of gastric juice and BCL2 in the quercetin-treated group. These results suggest that quercetin decreases gastric acidity through anti-apoptotic mechanisms. Similar results were reported about the antacid drug, omeprazole, which leads to a decrease in gastric acidity and thus a decrease in the development of gastric ulcers via antiapoptotic mechanisms (41). In conclusion, melatonin and quercetin have significant gastroprotective effects against indomethacininduced gastric ulcers due to their significant antioxidant, anti-inflammatory and antiapoptotic effects.

\section{Acknowledgment}

This research was funded by the Deanship of Scientific Research at Princess Nourah bint Abdulrahman University through the Fast-track Research Funding Program.

induced by indomethacin in tumor necrosis factor receptor 1 (TNF-R1) or inducible nitric oxide synthase (iNOS) deficient mice. Gut. 2004;53(6):791-6.

7. Scarpignato C, Hunt RH. Nonsteroidal antiinflammatory drug-related injury to the gastrointestinal tract: clinical picture, pathogenesis, and prevention. Gastroenterol Clin North Am. 2010;39(3):433-64.

8. Miederer SE. [Will anti-ulcer drugs soon differ only in their side effects?]. Fortschr Med. 1986;104(3):918-20.

9. Borrelli F1, Izzo AA. The plant kingdom as a source of anti-ulcer remedies. Phytother Res. 2000;14(8):581-91.

10. Yao LH, Jiang YM, Shi J, et al. Flavonoids in food and their health benefits. Plant Foods for Human Nutrition. 2004;59(3):113-122.

11. Mota KS, Dias GE, Pinto ME, Luiz-Ferreira A, Souza-Brito AR, Hiruma-Lima CA, Barbosa-Filho JM, Batista LM. Flavonoids with gastroprotective activity. Molecules. 2009;14(3):979-1012.

12. Kahraman A, Erkasap N, Koken T, Serteser M, Aktepe F, Erkasap S. The antioxidative and antihistaminic properties of quercetin in ethanol- 
induced gastric lesions. Toxicology. 2003;183(13):133-42.

13. Galano A, Tan DX, Reiter RJ. Melatonin as a natural ally against oxidative stress: a physicochemical examination. J Pineal Res. 2011;51(1):1-16.

14. Yamasaki K, Ishiyama H, Imaizumi T, Kanbe T, Yabuuchi Y. Effect of OPC-12759, a novel antiulcer agent, on chronic and acute experimental gastric ulcer, and gastric secretion in rats. Jpn $\mathbf{J}$ Pharmacol. 1989;49(4):441-8

15. Noriyoshi S, Masaru Y, Takemi G, Yoshimitsu A. Stimulation of prostaglandin E2 and interleukin$1 \beta$ production from periodontal ligament cells of old rat subjected to mechanical stress. J Gerontol A Biol Sci Med Sci. 2000;55(10): B489-95.

16. Othman AI, El-Missiry MA, Amer MA. The protective action of melatonin on indomethacininduced gastric and testicular oxidative stress in rats. Redox Rep. 2001;6(3):173-7.

17. Nishida K, Ohta Y, Ishiguro I. Relation of inducible nitric oxide synthase activity to lipid peroxidation and nonprotein sulfhydryl oxidation in the development of stress-induced gastric mucosal lesions in rats. Nitric Oxide. 1998;2(4): 215-23.

18. Peskar BM, Ehrlich K, Peskar BA. Role of ATP-sensitive potassium channels in prostaglandin-mediated gastroprotection in the rat. J Pharmacol Exp Ther. 2002;301(3):969-74.

19. Kiernan, JA. Histological and Histochemical Methods: Theory and Practice. 3rd ed. New York \& New Delhi: Arnold publisher. 2001. p. 111-162.

20. Livak KJ, Schmittgen TD. Analysis of relative gene expression data using real-time quantitative PCR and the 2(-Delta Delta C(T)) Method. Methods. 2001;25(4):402-408.

21. Ohkawa H, Ohishi N, Yagi K. Assay for lipid peroxides in animal tissues by thiobarbituric acid reaction. Anal Biochem. 1979;95(2):351-8.

22. Bradford MM. A rapid and sensitive method for the quantitation of microgram quantities of protein utilizing the principle of protein-dye binding. Anal Biochem. 1976; 72:248-54.

23. Griffith OW. Determination of glutathione and glutathione disulfide using glutathione reductase and 2-vinylpyridine. Anal Biochem. 1980;106(1):207-12.
24. Grisham MB, Johnson GG, Gautreaux MD, Berg RD. Measurement of nitrate and nitrite in extracellular fluids: A window to systemic nitric oxide metabolism. ELSEVIER. 1995;7(1):84-90.

25. Wallace JL, McKnight W, Reuter BK, Vergnolle N. NSAID-induced gastric damage in rats: requirement for inhibition of both cyclooxygenase 1 and 2. Gastroenterology. 2000;119(3):706-14.

26. Takeuchi K, Amagase K. Roles of Cyclooxygenase, Prostaglandin E2 and EP Receptors in Mucosal Protection and Ulcer Healing in the Gastrointestinal Tract. Curr Pharm Des. 2018;24(18):2002-2011.

27. Alkushi AGR, Elsawy NAM. Quercetin attenuates, indomethacin-induced acute gastric ulcer in rats. Folia Morphol (Warsz). 2017;76(2):252-261.

28. Ibrahim RM, Allam MM, El-Gohary OA, ElTalees AE, El-Hamady MS. Protective effect of obestatin on indomethacin-induced acute gastric ulcer in rats: role of VEGF and TNF- $\alpha$. Benha Med J. 2018;35(3):369-377.

29 Cuesta S, Kireev R, Garcia C, Forman K, Escames G, Vara E, et al. Beneficial effect of melatonin treatment on inflammation, apoptosis and oxidative stress on pancreas of a senescence accelerated mice model. Mech Ageing Dev. 2011;132(11-12):573-82.

30. Konturek SJ, Konturek PC, Brzozowski T. Melatonin in gastroprotection against stressinduced acute gastric lesions and in healing of chronic gastric ulcers. J Physiol Pharmacol. 2006;57(Suppl 5):51-66.

31. Carrasco-Pozo C, Castillo RL, Beltran C, Miranda A, Fuentes J, Gotteland M. Molecular mechanisms of gastrointestinal protection by quercetin against indomethacin-induced damage: role of NF-kB and Nrf2. J Nutr Biochem. 2016; 27:289-98.

32. Tanaka A, Araki H, Hase S, Komoike Y, Takeuchi K. Up-regulation of COX-2 by inhibition of COX-1 in the rat: a key to NSAID-induced gastric injury. Aliment Pharmacol Ther. 2002;16(Suppl 2):90-101.

33. Pal P, Bhattacharjee B, Chattopadhyay A. and Bandyopadhyay D. Melatonin as an armament against non-steroidal anti-inflammatory drug 
induced gastric injury: An overview. Melatonin Research. 2019; 2:115-137.

34. Slomiany BL, Slomiany A. Role of endothelinconverting enzyme-1 in the suppression of constitutive nitric oxide synthase in rat gastric mucosal injury by indomethacin. Scand $\mathbf{J}$ Gastroenterol. 2000;35(11):1131-6.

35. Holian O, Wahid S, Atten MJ, Attar BM. Inhibition of gastric cancer cell proliferation by resveratrol: role of nitric oxide. Am J Physiol Gastrointest Liver Physiol. 2002;282(5):G809-16.

36. Maity P, Bindu S, Dey S, Goyal M, Alam A, Pal C, et al. Melatonin reduces indomethacininduced gastric mucosal cell apoptosis by preventing mitochondrial oxidative stress and the activation of mitochondrial pathway of apoptosis. $\mathbf{J}$ Pineal Res. 2009;46(3):314-23.

37. Kusuhura H, Komatsu H, Sumichika H, Sugahara K. Reactive oxygen species are involved in the apoptosis induced by nonsteroidal antiinflammatory drugs in cultured gastric cells. Eur J Pharmacol. 1999;383(3):331-7.
38. Ishikawa $\mathrm{Y}$, and Kitamura M. Anti-apoptotic effect of quercetin: intervention in the JNK- and ERK-mediated apoptotic pathways. Kidney Int. 2000;58(3):1078-87.

39. Refolo MG, D'Alessandro R, Malerba N, Laezza C, Bifulco M, Messa C, et al. AntiProliferative and Pro Apoptotic Effects of Flavonoid Quercetin Are Mediated by CB1 Receptor in Human Colon Cancer Cell Lines. J Cell Physiol. 2015;230(12):2973-80.

40. Srivastava S, Somasagara RR, Hegde M, Nishana M, Tadi SK, Srivastava M, et al. Quercetin, a Natural Flavonoid Interacts with DNA, Arrests Cell Cycle and Causes Tumor Regression by Activating Mitochondrial Pathway of Apoptosis. Sci Rep. 2016; 6:24049.

41. Biswas K, Bandyopadhyay U, Chattopadhyay I, Varadaraj A, Ali E, Banerjee RK. A novel antioxidant and antiapoptotic role of omeprazole to block gastric ulcer through scavenging of hydroxyl radical. J Biol Chem. 2003;278(13):10993-1001. 